\title{
EL ESTADO SEGÚN LOS ALTOS FUNCIONARIOS DE LA HACIENDA ESPAÑOLA, 1881-1936
}

\author{
JUAN PAN-MONTOJO \\ Universidad Autónoma de Madrid \\ juanluis.pan@uam.es
}

(Recepción: 19/05/2015; Revisión: 29/09/2015; Aceptación: 28/12/2015; Publicación: 02/12/2016)

\begin{abstract}
1. LA HACIENDA PÚBLICA Y SUS ÉLITES EN EL SIGLO XIX.-2. LA LLEGADA DE LOS CUERpos a HaCienda.-3. Los discursos CORPORATIVOS y el Estado.-4. CONClusioNES.-5. BIBLIOGRAFÍA
\end{abstract}

\begin{abstract}
RESUMEN
Este artículo presenta los elementos comunes de las visiones del Estado entre los cuerpos especiales y las clases superiores del cuerpo general de Hacienda entre las décadas finales del siglo XIX y la Guerra Civil. Se organiza en tres partes. Las dos primeras describen, respectivamente, los grandes rasgos del modelo administrativo que se impuso en Hacienda tras las reformas de Bravo Murillo y la evolución de este modelo a partir de 1881, gracias a la construcción de cuerpos especiales, llamados a convertirse en la referencia de la evolución del Ministerio. La tercera parte enumera los elementos centrales de las visiones de Estado que se desprenden de diversos discursos públicos de estos altos funcionarios hacendísticos. Se destacan en este último ámbito tres rasgos que se hallaban conectados con la evolución anterior de la propia burocracia hacendística: la ecuación del Estado con la Administración; la conversión del conocimiento técnico especializado en el fundamento mismo de la carrera funcionarial; y una visión organicista de la Administración (entendida como esencia del Estado) que remite el buen funcionamiento de esta al de sus partes componentes.
\end{abstract}

Palabras clave: Hacienda; funcionarios; abogados del Estado; construcción del Estado; imaginario de Estado. 


\title{
THE STATE ACCORDING TO THE HIGH CIVIL SERVANTS OF THE SPANISH MINISTRY OF FINANCES, 1881-1936
}

\begin{abstract}
This article presents the common elements of the visions of the State among the special corps and superior classes of the general corps of the Ministry of Finance between the final decades of the 19th century and the Civil War. It is organised in three parts. The two first parts describe the general traits of the administrative model that became hegemonic in the Ministry after the reforms of Bravo Murillo and the evolution of this model after 1881, thanks to the multiplication of special corps, which were to become the reference of the evolution of the Ministry. The third part sums up the central elements in the comprehension of the State, which can be derived from the different public discourses of the civil servants who worked for the Ministry of Finance. Three features, which were linked to the previous evolution of the tax administration, are underlined in the third section. Firstly, the understanding of the State as Administration. In the second place, the generalised assumption of technical and specialised knowledge as the very foundation of the bureaucratic career. And, finally, an organicist vision of the Administration (understood as the essence of the State) which referred its good working to the good working of its component parts.
\end{abstract}

Keywords: Treasury; civil servants; State attorneys; State-building; State imaginaries.

$$
* \quad * \quad *
$$

En todos los procesos históricos de construcción del Estado, la administración hacendística ha jugado un papel clave por cuanto que es la encargada de proporcionar los medios materiales del despliegue estatal, sobre la base además de un mecanismo redistributivo, la fiscalidad, que constituye una parte esencial del vínculo político. Pero en el caso español a esa relevancia, sobre todo aunque no únicamente instrumental, cabe agregar otra dimensión. A lo largo del siglo XVIII, la evolución desde la concepción jurisdiccional a la concepción gubernativa del poder y las tensiones suscitadas entre el gobierno político y económico de los pueblos y el gobierno de la Monarquía se asociaron de forma constante a las novedades institucionales, jurisdiccionales y políticas de la fiscalidad. La propia economía política, que incluía en un lugar destacado la cuestión fiscal, apareció como proyecto intelectual de diferenciación de la sociedad civil y la sociedad política: de ahí que el reformismo político dieciochesco se expresara a menudo en términos de reforma de los tributos, los gastos y la planta de Hacienda (1).

La Hacienda española no perdió en el tránsito del Antiguo Régimen al sistema político liberal el carácter de institución central del debate político. De hecho se convirtió en el escenario fundamental de muchos de los conflictos

(1) Tal y como se señala en PAN-Montojo (2014): 51-52. La «diferenciación» en GARCíA MONERRIS (2000). 
desatados por el avance del liberalismo: las desamortizaciones, la reforma tributaria de 1845, la aprobación de los sucesivos aranceles y el crédito público interior y exterior llegaron a ser las grandes cuestiones conflictivas durante el proceso de desarrollo del nuevo Estado y la protesta fiscal estuvo omnipresente en la acción colectiva y en la movilización revolucionaria. Pero si en el siglo XVIII la organización político-administrativa de la Hacienda había sido la punta de lanza de las reformas de la Monarquía, en el XIX su dinamismo fue mucho menor: únicamente en la década de 1880 se introdujeron cambios llamados a marcar la pauta para los que configuraron una nueva administración ya en el siglo XX. Hasta entonces, los empleados de Hacienda mantuvieron todos los atributos de una corporación de oficios públicos. Provistos de canales de acceso y promoción fundados en el favor clientelar, de una jurisdicción especial, de una fuerza armada propia y de oficinas especiales en las provincias, eran sin duda el componente más autónomo, con mayor nivel de autogobierno, de los aparatos públicos civiles, esto es si no incluimos el Ejército (2). Esa autonomía permitió a sus miembros resistir con éxito determinadas reformas administrativas y reconducir hacia sus rutinas anteriores muchas de las novedades fiscales.

Las transformaciones en el terreno del personal y la génesis del modelo funcionarial que se acabaría imponiendo en la Administración Pública en el siglo Xx tuvieron lugar en otro Ministerio, el de Fomento. En este centro nacieron los primeros cuerpos especiales, los cuerpos de ingenieros, en los que se combinaron continuidades con tradiciones hispanas, particularmente con las gestadas en algunas armas del Ejército y la Marina en el XVIII, con criterios de reclutamiento, pautas formativas y discursos nuevos hasta dar lugar a un modelo distinto de funcionario (3). Los cuerpos de ingenieros civiles reproducían el formato y el espíritu de corporaciones estamentales aunque con criterios de selección meritocráticos, una formación tecno-científica y un discurso de servicio a la nueva noción abstracta de Estado (4). Se trataba de funcionarios inamovibles cuya promoción dependía de la antigüedad y del mérito probado ante sus pares. Tenían además un elevado nivel de autogobierno y una posición potencialmente privilegiada en términos de sueldo, por cuanto que el reparto entre categorías de sus integrantes era objeto de una regulación específica. Finalmente, los ingenieros ascendían incluso cuando se hallaban fuera del servicio activo y disfrutaban de posibilidades de excedencia ilimitadas, con lo que podían transitar del espacio público al privado, del empleo funcionarial al ejercicio liberal o asalariado de la profesión, hasta el punto de difuminar los límites entre ambas esferas (5).

(2) Martínez PÉREZ (2009).

(3) Sobre el papel que estaban llamados a tener los cuerpos especiales en la Administración española, hay que recordar las reflexiones de GARCía DE EnTERRÍA (1995 [1972]): 78 y 121-18.

(4) MARTYKÁNOVÁ (2007).

(5) Una caracterización completa de las especificidades de los cuerpos de ingenieros en VILLACORTA (1989): 46-49. 
En Hacienda, el primer cuerpo funcionarial con rasgos semejantes a los de caminos y minas fue el de Aduanas. Pero sus integrantes tenían competencias periféricas desde todos los puntos de vista respecto a la corporación de empleados que dominaban el Ministerio. Estos últimos, los conocidos despectivamente como «covachuelistas» de Hacienda, desempeñaban tareas a menudo difíciles de diferenciar de las de sus antecesores en el siglo XVIII como la negociación con los pueblos de los cupos fiscales y la supervisión y, en el límite, el control de la gestión municipal y provincial, además de otras nuevas funciones como la elaboración de presupuestos, la administración de la deuda y de las propiedades del Estado... (6). En los orígenes del desarrollo administrativo de lo que Comín ha llamado una «Hacienda transicional» estuvieron precisamente las reformas que en 1881 introdujo Camacho en Hacienda (7): la institución de las delegaciones de Hacienda y la creación del cuerpo de abogados del Estado. Ambas novedades sentaron una pauta para la transformación del modelo corporativo de Hacienda. Pero además hicieron del Ministerio el centro de la movilización y la reforma funcionarial en los años anteriores a la Gran Guerra. Como en el siglo XVIII, los discursos sobre la organización y las cuestiones relativas a la administración interior del Ministerio pasaron a tener un alcance mucho mayor, proyectándose sobre la evolución de los aparatos burocráticos y de los imaginarios de Estado que sustentaban.

Analizar las relaciones entre ese rearme de Hacienda como centro administrativo con arreglo a nuevas pautas corporativistas y la renovación de la visión del Estado por parte de sus empleados es el objeto de este artículo. Se trata de un acercamiento al proceso de construcción del Estado que pretende continuar pero también trascender el desarrollado en las últimas décadas por los administrativistas y los historiadores del derecho: continuar porque la perspectiva desde la que se mira -la de los empleados públicos, su organización y su papel- es semejante; trascender porque son las experiencias y discursos de los funcionarios en el Ministerio que consideramos clave, en particular de sus élites internas, y no la doctrina ni la normativa, lo que constituye el eje de nuestro análisis. Nuestro propósito es avanzar en una historia social y cultural de los funcionarios y, en concreto, de los que sostendremos que llegaron a constituir uno de sus elementos cuantitativa, cultural y políticamente centrales, los de Hacienda, para abrir una nueva perspectiva para la historia del Estado en la España contemporánea.

(6) GARriga y LoRENTE (2007): 324.

(7) La Hacienda transicional, situada cronológicamente entre 1899 y 1936, estaría caracterizada según Cомín (1988) por un gradualismo reformista, orientado a reunir conocimiento sobre las bases fiscales y diversificar y ampliar los hechos imponibles para alcanzar la suficiencia y diversificar el gasto, sobre todo en el sentido de aumentar el social. 


\section{LA HACIENDA PÚBLICA Y SUS ÉLITES EN EL SIGLO XIX}

A un ministro de Hacienda, cargo que compaginaba por entonces con el de presidente del Gobierno, Bravo Murillo, se debe la primera norma de carácter general sobre empleados públicos: el RD de 18 de junio de 1852. Con este decreto se sentaron las normas orgánicas de los cuerpos generales administrativos, excluidos por tanto los cuerpos especiales, hasta 1918. Su articulado fijó las categorías administrativas (salvo los puestos llamados subalternos), las clases dentro de cada una de ellas, sus sueldos y la forma de acceso, que incluía la necesidad de pasar una oposición para entrar en la categoría inicial de oficiales (aunque hasta un tercio de las plazas se pudieran cubrir directamente con aspirantes), los órganos disciplinarios y de personal y los derechos y obligaciones de sus miembros. También reguló la promoción entre categorías y dentro de estas. Pero frente a otros modelos europeos de funcionarios, adoptados también por regla general en el segundo tercio del siglo XIX, el español no exigía ninguna titulación académica formal, aunque para presentarse a aspirante sí resultase necesario «tener título académico o diploma que presuponga estudios, y la conveniente preparación, o haber obtenido calificación favorable en examen público» (art. 13.3) (8). Un segundo rasgo del modelo creado por Bravo Murillo era que los funcionarios ministeriales (a veces llamados de los cuerpos generales, por contraposición a los cuerpos especiales) no eran inamovibles: es más, el artículo 44 del citado decreto señalaba que los funcionarios no podrían pedir explicación escrita de su separación, suspensión o traslado (9). Con ello se abría la puerta de par en par a la cesantía, la separación de funcionarios por decisión de sus jefes: carecemos de una serie continuada de cesantes pero su número fue importante a lo largo del siglo, reflejo del uso de los empleos administrativos como caja de recompensas, por cuanto que los cesantes hacían hueco a la entrada de «recomendados», clientes políticos o personales de los dirigentes ministeriales (10). En tercer lugar, la carrera profesional se vinculaba a la antigüedad pero dejando un amplio margen a las decisiones de los jefes, lo que de nuevo, según todos los indicios, favorecía el desarrollo de las lealtades personales y políticas. En cuarto lugar, ni en el reclutamiento ni en la promoción de empleados se atuvieron las sucesivas direcciones ministeriales a las normas de 1852: en el Sexenio se anularon disposiciones de 1864 y 1865 y, tras una

(8) En Francia y los estados alemanes se exigían por el contrario títulos formales de centros concretos o de la enseñanza secundaria o superior al menos para ciertos cuerpos, aunque en Francia esas exigencias no se generalizasen hasta la III República: DREYFus (2000): 174-178. En el Reino Unido a partir de la reforma de 1854 se optó por un examen público de carácter muy generalista, que tendió a favorecer a los licenciados de Oxford y Cambridge: RAPHAEL (2000): 169-172.

(9) Sobre la importancia de este artículo y para un comentario más amplio, véase VILLACORTA (1989): 57-60.

(10) La figura del cesante, a partir de fuentes literarias, en AlbuERA (1990). VILLACORTA (1989: 60) ofrece algunas cifras para la década de 1890. 
encendida denuncia del clientelismo en la Administración por parte de los gobiernos anteriores, se decidió de forma paradójica que el ingreso y el ascenso quedaran al arbitrio de los ministros (11). Probablemente un estudio de las hojas de servicio de los funcionarios nos permitiría añadir nuevos rasgos relativos a los ciclos generacionales-políticos de los empleados contratados bajo este modelo: los escalafones y las semblanzas de los delegados provinciales de Hacienda, publicadas por Revista de Hacienda en 1911, revelan que hubo momentos políticos de especial intensidad en la contratación de empleados que tendieron a restringir las entradas y a condicionar la promoción en años posteriores. Entre ellas cabe destacar la segunda mitad de la década de 1820 y la primera de la de 1830, el Sexenio y los primeros años de la Restauración y la década de 1890 (12).

De las consecuencias que se derivaban de estas fórmulas de reclutamiento y promoción se escaparon los llamados cuerpos especiales que tenían una regulación propia. Bravo Murillo creó en Hacienda dos ramos entre los empleados de la Renta de Aduanas, el pericial y el no pericial, y convirtió el primero en un cuerpo especial cuyos miembros, ingresados mediante oposición, gozaban de la inamovilidad (13). Pero como ya hemos señalado en la introducción, el Cuerpo de Aduanas no llegó a convertirse en un cuerpo de élite de Hacienda. Su configuración era distinta a la de los cuerpos de ingenieros -empezando por la inexistencia de una escuela especial de formación y la falta de exigencia de títulos académicos superiores para el ingreso y siguiendo por su inferior capacidad de autorregulación a otros niveles (disciplina, promoción...)- pero además mientras que en Fomento los ingenieros tenían esferas propias que eran centrales entre las competencias de su Ministerio, los funcionarios de Aduanas se encargaban de una tarea de una entidad política menor. Por otra parte, sus destinos en las aduanas terrestres y marítimas no contribuían a aumentar su peso en los centros políticos. Su temprano, y ambiguo, cuerpo especial no hizo de ellos la élite de Hacienda.

Hasta 1881, ningún otro cuerpo ocupó esa posición y la vida ministerial estuvo dominada por los empleados de Hacienda, los que ya en el siglo XX se conocerían como funcionarios de la Administración general de Hacienda. Estos conformaban un grupo relativamente grande y muy heterogéneo desde todos

(11) GUTIÉRREZ REÑóN (1987): 32-33.

(12) Precisar estas fechas queda para un trabajo ulterior. En LuIs (2002) se explica la depuración y el acceso de empleados durante la etapa de reformismo absolutista. Las referencias a la amplia contratación de empleados por parte de los gobiernos de la década de 1830 es una constante de la literatura de la época: véanse por ejemplo los comentarios a los cambios que habían tenido lugar en las oficinas públicas en «El cesante», escrito en 1837 por MESONERO ROMANOS (1975). Los otros periodos se desprenden de un análisis preliminar de los escalafones de la Hacienda Pública a principios del xx y de las semblanzas de los delegados de Hacienda que se publicaron en la Revista de Hacienda.

(13) PRO (2007): 12-13. 
los puntos de vista, que iba desde los aspirantes a una reducida cúpula de jefes superiores de la Administración. Pero en su seno todo apunta que a lo largo del siglo XIX existieron redes de poder estables -aunque desde luego renovadas en el tiempo- alrededor de funcionarios consolidados y políticos especializados en materias económicas: una realidad que podemos adivinar a través de diferentes indicios. En primer lugar, algunos retratos literarios y ensayos satíricos de época insisten en las conexiones políticas y personales de los empleados que lograron mayor éxito en sus trayectorias (14). Estos testimonios subrayaban asimismo las posibilidades que abría el cursus honorum burocrático para forjarse una carrera política, algo que, ya no solo en relación a Hacienda, también ponen de relieve algunos estudios prosopográficos recientes (15). Por su parte, las biografías de ciertos ministros reflejan el funcionamiento de mecanismos de promoción de empleados hasta cargos políticos así como la importancia de las conexiones familiares entre funcionarios-políticos. Ramón Santillán, asesor de los principales ministros de Hacienda de la Década Moderada, Mon y Bravo Murillo, y dos veces ministro él mismo, había trabajado en el Ministerio desde 1825 (16). Los hermanos García Barzanallana, Manuel y José, hijos de Juan García Barzanallana que alcanzó la dirección general de Aduanas en los años cuarenta tras muchos años en las oficinas hacendísticas madrileñas, entraron ambos en fechas tempranas como funcionarios y llegaron a ministros, tres veces el primero, en el reinado de Isabel II, y una el segundo, en la Restauración (17). Pedro Salaverría, empleado de Hacienda desde 1834, llegó a director general del Tesoro en 1845 y ocupó otros cargos, incluido el de subsecretario del Ministerio en 1855, siendo nombrado ministro por primera vez en 1856; en 1857

(14) ANAYA (1844), en Los españoles pintados por sí mismos, ya aludía a la continuidad natural entre la carrera funcionarial y la política entre el nuevo tipo de empleados que había traído consigo el régimen constitucional. E. O. H. (1872) satirizaba la figura de los empleados volcados a apoyar carreras políticas. GARCía Solís (s. a.) nos cuenta toda su trayectoria desde que entró en Hacienda en 1845 hasta 1900: no escatima detalle sobre quién lo colocó en cada nivel y puesto, empezando por su primer empleo en Hacienda en Oviedo que le proporcionó aparentemente Mon, ni sobre cuándo y por obra de quién fue declarado cesante. Los empleos le fueron facilitados inicialmente por políticos relacionados con su familia y paisanos asturianos, pero gradualmente fueron decisivos otros empleados de Hacienda y políticos a los que fue conociendo a lo largo de su dilatado cursus honorum. García Solís publica en su obra algunas de sus cartas de petición de puestos y las que recibió en respuesta: esa publicación refleja que el autor no consideraba en modo alguno ilegítima la lógica del favor y la recomendación.

(15) BuRdiel y Romeo (1993) destacan el peso de los abogados y empleados entre los parlamentarios. CUENCA y MiRANDA (1992) aluden por su parte al elevado número de antiguos empleados o cargos administrativos entre los ministros de la Restauración. Llegar a la política por medio del trabajo en la Administración y triunfar en la carrera funcionarial gracias a las conexiones y al capital político no es lo mismo. No obstante, pensamos que quizá lo importante no fuera exactamente el orden (de la Administración a la política o de la política a la Administración) sino el capital social acumulado en los centros administrativos y políticos, susceptible de aplicación a trayectorias de sentidos cambiantes.

(16) VALLeJo (2006).

(17) GaRcía (2006). 
pasó otra vez por el cargo brevemente, volvió a la cartera entre 1858 y 1864 y todavía una cuarta al inicio del régimen canovista (18).

La corporación de empleados de Hacienda era la más numerosa de la Administración civil: en 1848, sus 1.037 efectivos en Madrid eran el 33,34 \% de los empleados del Estado en la capital; en 1869, los 4.717 empleados de Hacienda en toda España, suponían el 34,13\% de los empleados de todos los ministerios civiles (19). La concentración de los oficiales y jefes de Hacienda en Madrid era, según todos los indicios, muy alta: en 1859-1860 el gasto en personal del Ministerio (excluido el coste del cuerpo de carabineros) se distribuía en un $72 \%$ para Madrid y un $28 \%$ para provincias (20). La centralización de los empleados ministeriales en la capital traducía las necesidades funcionales del sistema tributario y del gasto público. En la mayor parte de las figuras impositivas ni el Estado conocía ni la clase política pretendía que conociera las bases sobre las que se cobraban: la negociación de cupos con los ayuntamientos, las diputaciones y las agremiaciones fiscales era una tarea que exigía poco personal. Por su parte el gasto se hallaba muy concentrado en los aparatos centrales del Estado y en el pago de la deuda, por lo que tampoco desde ese punto de vista resultaba relevante una burocracia repartida en el territorio. La única excepción era la exigida por las fronteras.

En la década de 1860 y, especialmente, en el Sexenio se trató de ir superando gradualmente este esquema hacendístico que había resultado clave para el éxito de la primera fase de construcción del Estado nacional, en el contexto del desmoronamiento del Imperio y los conflictos interiores. En el plano estrictamente administrativo, configurar una fiscalidad más relacionada con la capacidad de pago de los contribuyentes y fundada en mecanismos burocráticos «rutinarios» pasaba por mejorar la información y formar expertos en tareas de gestión, inspección y recaudación. La especialización en tareas de inspección o de seguimiento de impuestos concretos dentro del cuerpo de empleados de Hacienda fue una primera vía ensayada. Los cambios fueron sin embargo poco duraderos porque los problemas políticos de la monarquía democrática y la república, primero, y la restauración borbónica, después, paralizaron los proyectos reformistas. Cuando en 1881 la oposición liderada por Sagasta regresó al poder, se avanzó por un camino parcialmente diferente aunque con objetivos semejantes de preparar la maquinaria hacendística para adaptarla a una fiscalidad fundada en mayor medida en la exacción de cuotas sobre bases tributarias objetivas que en la negociación de cupos.

(18) SERRANO (2006).

(19) Las cifras exactas de funcionarios de las diversas administraciones resultan especialmente difíciles de precisar. Estos datos están sacados de Moral (2007: 121-139).

(20) Calculado a partir de los datos ofrecidos por Anuario (1860: 222-224). 


\section{LA LLEGADA DE LOS CUERPOS A HACIENDA}

En 1881 fue nombrado ministro de Hacienda, en el primer gabinete de Sagasta, Juan Francisco Camacho, que ya había ocupado la Subsecretaría del Ministerio en 1866 y la cartera ministerial en 1872 y 1874 (21). Este hombre, cuya carrera hacendística se había iniciado bajo el manto protector de Alejandro Mon, aprobó un largo número de decretos y presentó un paquete de leyes que suponían una reforma de la administración político-económica apenas un mes después de su nombramiento. Su plan, que reflejaba la existencia de un proyecto previo, tuvo en dos plasmaciones inmediatas: la institución de las delegaciones de Hacienda y la creación del Cuerpo de Abogados del Estado.

Las delegaciones de Hacienda venían a separar la administración provincial del ramo de los gobiernos civiles, de los que hasta entonces habían dependido sus antecesoras, las administraciones provinciales (22). Esto suponía que los empleados hacendísticos en todo el país respondieran ante delegados nombrados directamente por el ministro y quedaran por tanto, y en principio, al margen de las consideraciones políticas más directas que presidían la gestión de los representantes de Gobernación. Desde otra perspectiva, la institución de las delegaciones implicaba que cara al futuro las relaciones entre el Gobierno y el territorio tendiesen a quedar compartimentadas por ministerios. En segundo lugar, las delegaciones recibieron una nueva planta: de las tres áreas de las administraciones anteriores -administrativa, interventora y caja-, se pasó a una cuatripartita en un primer momento -administración de contribuciones y rentas, administración de propiedades e impuestos, tesorería e intervención- aunque abierta en la práctica al crecimiento y especialización de las funciones: se articulaba la posibilidad de una estructura más compleja, y más determinada por las figuras tributarias concretas, que gradualmente se iría desplegando. Las delegaciones fueron, en tercer lugar, el instrumento de un desarrollo administrativo mucho más equilibrado desde el punto de vista territorial, lo que iría permitiendo la sustitución del modelo de negociación de los impuestos con los ayuntamientos por otro de gestión directa y centralizada. A la altura de 1924, un $80 \%$ de los miembros del Cuerpo General de Hacienda estaban destinados en las delegaciones provinciales, lo que suponía todo un cambio respecto al panorama del XIX (23). La renovación de la planta territorial del Ministerio de Hacienda abrió en la práctica grandes posibilidades pero no supuso una discontinuidad con el modelo funcionarial existente; por el contrario sí lo hizo la institución del Cuerpo de Abogados del Estado.

(21) Comín y MaRTorell (2006).

(22) Sobre el significado organizativo y político de las delegaciones apenas hay estudios. Se presentan algunas observaciones generales en RozAS (1981) y PALACIOS (1981).

(23) Hacienda Española (1924): 184. 
El nuevo cuerpo, llamado a ofrecer personal a la Dirección general de lo Contencioso, el organismo encargado de los negocios jurídicos de Hacienda y de todo el Estado, era el resultado de la transformación de uno anterior, el de Oficiales Letrados de Hacienda, creado por la Ley de 29 de mayo de 1868 para la calificación de qué contratos se hallaban sometidos al impuesto de traslaciones de dominio. Esta tarea sería pronto una de las principales misiones tributarias de los abogados del Estado, que debían compatibilizar con su asesoría jurídica al Ministerio -y ya en los años noventa a otros ministerios también- y «la dirección de todos los negocios del Estado que se ventilen ante los Tribunales ordinarios», según rezaba el artículo primero del Real Decreto de 10 de marzo de 1881. La amplitud de las funciones del nuevo cuerpo estuvo acompañada de su configuración como cuerpo especial, un rasgo que no poseían sus antecesores los letrados (24): entrada por oposición, ascenso por antigüedad (aunque se preveía en el decreto inicial que un tercio de las vacantes se cubrieran por elección y luego se reglamentaron los concursos de méritos) e inamovilidad. El cuerpo de Hacienda y sobre todo las categorías superiores que regían esa corporación se enfrentaron de este modo a la aparición de un cuerpo especial con competencias amplias, incluida una específicamente tributaria, en el seno del Ministerio. Un cuerpo cuyos integrantes eran licenciados, destinados además a ocupar niveles relativamente elevados en la jerarquía de categorías y clases, y cuyo ascenso por antigüedad los sustraía de los mecanismos imperantes en Hacienda, constituía una ruptura. No es por ello de extrañar que cuando accedió a la cartera en 1884 el conservador Cos-Gayón, que había ocupado puestos importantes en Hacienda desde 1875, decidiera suprimir la abogacía del Estado. Sin embargo al año siguiente, con el regreso de Camacho, el cuerpo fue restablecido y sus funciones ampliadas. Se iniciaba así una transformación del modelo administrativo de Hacienda que se reforzó especialmente a partir del cambio de siglo.

Siguiendo la pauta del nuevo cuerpo especial, el 14 de agosto de 1900 se creó el Cuerpo de Ingenieros de Montes al servicio de Hacienda, a fin de gestionar los llamados montes de Hacienda, aunque en 1906 adquirieron funciones tributarias. Al año siguiente, en 1907, se estableció el Cuerpo de Profesores mercantiles al servicio de la Hacienda Pública, al que se le encargó la inspección de la contribución de utilidades (25). Un nuevo Cuerpo, el Pericial de Contabilidad del Estado, que pasó a englobar a quienes ya de hecho ejercían labores técnicas en la Intervención General de Estado, fue establecido en 1913 (26). En 1915, se creó el Cuerpo de Ingenieros Industriales al servicio de la Hacienda Pública, a los que se atribuyó la inspección de la contribución

(24) La amplitud de las tareas y una propuesta de limitar los supuestos de intervención de la abogacía del Estado en Dirección General de lo Contencioso (1899).

(25) GARCÍA GARCÍA (2007): 36.

(26) CAnsino (2001). 
industrial, del gas, electricidad, carburo de calcio y de alcoholes (27). Todos estos cuerpos se caracterizaban por la necesidad de contar con títulos específicos para el ingreso - de ahí su reconocimiento como cuerpos facultativos o técnicos- así como por el acceso mediante oposición o mediante escuelas especiales, pero a diferencia del de Abogados del Estado, sus funciones eran muy especializadas.

El grueso de los funcionarios de Hacienda, el $70 \%$ de los empleados no auxiliares incluidos en el escalafón de 1928, acabaron sin embargo englobados en un Cuerpo General de la Administración de la Hacienda Pública (28). Aunque la Ley de Funcionarios de Hacienda de 29 de julio de 1904 replanteó las categorías personales de los empleados del Ministerio, garantizó cierta estabilidad en los empleos y definió los turnos de provisión de plazas, el Cuerpo General fue definitivamente creado como tal, con una escala técnica y otra auxiliar, en la Ley de Bases de la Función Pública de 22 de julio de 1918. Pese a que el nuevo cuerpo consiguió la inamovilidad, primero en la práctica y luego formalmente, en 1918, sus integrantes distaban mucho de ser un cuerpo especial: no solo por su tamaño y su falta de especialización, sino también por el hecho de que sus pruebas de acceso solo empezaron a exigir formación específica acreditada por un título (y únicamente el de bachiller) en 1917 y además se mantenían los turnos restringidos de ascenso para categorías auxiliares, lo que en la práctica suponía que se podía escalar en sus filas con meros estudios primarios, por más que eso fuera desde luego excepcional (29). Por ello, en 1926 se creó dentro del Cuerpo General un sistema de oposiciones especial para filtrar el acceso a la inspección: nacieron los diplomados para la inspección de tributos que, pese a no constituir un cuerpo por entonces, se situaban por encima de sus compañeros en términos de posibilidades de promoción. La decisión de 1926 suponía reforzar lo que por entonces se llamaban especialidades, contrapuestas en las publicaciones cercanas al Cuerpo General a los nuevos cuerpos especiales, pese a que en realidad acabaron abriendo la puerta a su multiplicación (30). Esa evolución se vio reforzada por las ventajas obtenidas durante la década de 1920 por diferentes cuerpos especiales, y muy singularmente por los de ingenieros y por el de abogados del Estado, en términos de remuneración, rompiendo la homogenización impuesta en 1918 como respuesta a los movimientos corporativistas de los empleados «no facultativos». El conocido como Estatuto de Maura de 1918 vino a ser un paso atrás limitado y de escasa efectividad en el proceso de disgregación corporativa de Hacienda

(27) García García (2007): 38-39.

(28) La cifra de miembros de la escala técnica del Cuerpo General de la Administración dee la Hacienda Pública está calculada a partir de los Escalafones (1929).

(29) JiMÉNEZ ASENSIO (1989).

(30) «Especialidades, sí; cuerpos especiales, no. La Administración de la Hacienda debe ser exclusiva del Cuerpo General Técnico-Administrativo», era el titular de portada de Hacienda Española, n. ${ }^{\circ} 41,17$. I. 1925. 
y de la función pública en general que se había iniciado mucho antes y avanzaría en años sucesivos (31).

En definitiva entre 1881 y la Guerra Civil se asistió a un proceso de transición entre el modelo de empleados generalistas, cuya contratación y promoción habían actuado como eficaces instrumentos políticos para captar lealtades y desplegar la red clientelar en la que se fundó la construcción del Estado liberal, y un nuevo modelo de cuerpos autorregulados, de diferentes grados de especialización técni$\mathrm{ca}$, regidos por el sistema de oposiciones competitivas. Fue un proceso algo posterior en el tiempo y con resultados diferentes, al que fue transformando el reclutamiento de empleados públicos en la segunda mitad del siglo XIX en el Reino Unido, Francia y Alemania: pero como en estos países trajo consigo la limitación del poder de los políticos en la contratación de empleados. Además de por el ejemplo extranjero, la transición se justificó en las carencias desde el punto de vista de la presencia y la eficacia administrativas de una burocracia decimonónica que a través de su empleo como «patrimonio político» servía más a la supervivencia y reproducción de las élites políticas -aunque con ellas sobreviviera y se reprodujera asimismo el proyecto de construcción del Estado que encarnaban- que, paradójicamente, a la consolidación del poder estatal, a la capacidad de este de imponer sus normas de forma cotidiana sin necesidad de negociaciones con las élites locales (32). Se utilizó como referencia la ofrecida por los cuerpos de ingenieros civiles para construir un cuerpo jurídico, el de abogados del Estado, cuya propia existencia empujó en la dirección de una nueva corporativización de Hacienda, sobre la base ya no del Ministerio como tal sino de funciones y conocimientos específicos de diferente tipo. Un proceso en el que cabe señalar dos particularidades: Hacienda actuó como modelo para los demás ministerios (su ley de funcionarios de 1904 fue la primera de una serie que acabó cubriendo los diferentes centros ministeriales); y dentro de Hacienda los abogados del Estado, convertidos normativa y socialmente en una élite reforzada por los sucesivos reglamentos de 1900, $1915 \mathrm{y}$, sobre todo, 1925, se transformaron en la referencia de los restantes altos funcionarios.

En 1918 se circunscribió a los miembros del Cuerpo general de la Hacienda Pública y a los del de Abogados del Estado y a los integrantes del Cuerpo pericial de Contabilidad, la posibilidad de ocupar el cargo de delegado de Hacienda (33). Desde luego pocos de sus miembros podían llegar a lo que era, con excepción de algunas de las direcciones generales, el máximo nivel alcanzable en el Ministerio. Esa equiparación formal, favorecida por el hecho de que eran

(31) NIETO (1967): 235-287.

(32) La relevancia de la burocracia decimonónica para acercarse a la historia política de esta centuria ha sido uno de los argumentos fundamentales de la obra de Alejandro Nieto: «la burocracia se convierte en un instrumento formidable en manos del Poder político» señalaba en NIETO (1986: 302). De este autor procede también la tesis de que la burocracia del XIX responde a una visión de la misma como «patrimonio político».

(33) Rubio BERMEJo (1981) 
las categorías superiores de los empleados de Hacienda las que venían ocupando la mayoría de las delegaciones desde 1881, constituía una victoria colectiva tanto más importante, por cuanto que la asimetría entre las cuerpos especiales, cuyos integrantes disfrutaban desde un principio de niveles administrativos (y por lo tanto de sueldos) más elevados, y la pirámide de amplia base de los generalistas, obraba claramente en contra de estos últimos (34). La cúspide de los empleados obtenía así réditos de la larga ofensiva del colectivo: acceder a la constitución del cuerpo general fue un objetivo manifiesto de los empleados de Hacienda entre finales del XIX y la Guerra Civil. Al mismo tiempo o tras la formación del cuerpo general los empleados dotados de conocimientos específicos intentaron formar sus propios cuerpos. En uno y otro nivel, se recurrió a diversas formas de acción colectiva, bien fuera pública o bien fuera discreta, con presiones sobre los responsables del Ministerio. En 1906 los empleados de la Delegación de Ourense pusieron en marcha una campaña de firmas que obtuvo un elevado respaldo en todo el país. La movilización de los empleados de Hacienda se repitió en 1911 y adquirió un tono mucho más combativo entre 1914 y 1918. En enero de 1921 llegó a haber una huelga de una única jornada en el Ministerio. Desde entonces y hasta la Guerra Civil predominaron los escritos colectivos y asociativos y los artículos en la prensa propia y generalista. Los rastros documentales dejados por estas campañas y por otras publicaciones vinculadas a los cuerpos y a quienes se arrogaban la calidad de sus representantes nos permiten acercarnos a sus visiones corporativas y a sus conexiones con los imaginarios del Estado.

\section{LOS DISCURSOS CORPORATIVOS Y EL ESTADO}

Hacia 1900, un antiguo delegado de Hacienda, García Solís, efectuó una cerrada defensa de la inamovilidad y de la creación de sistemas objetivos de acceso y promoción de los funcionarios del Ministerio, al tiempo que cargaba contra la tendencia a «dividir en castas los empleados, en técnicos y no técnicos o legos», perjudicando a estos últimos pese a ser el «nervio de la Hacienda» (35). Eliminar la diferencia entre técnicos y no técnicos, como preconizaba García Solís, dejó pronto paso a una estrategia semejante pero con acentos distintos: hacer de los empleados de Hacienda técnicos o, al menos, igualar sus condiciones con la de estos. Un primer hito en ese sentido fue la Ley de Funcionarios de Hacienda de 1904, un paso sin embargo considerado insuficiente. En 1905 se inició la publicación de Revista de Hacienda. Semanario profesional y defensor de los intereses del personal. La aparición de esta revista fue a la vez un síntoma

(34) García Solís (s. a.): 72, acusaba a los interventores de copar las delegaciones y de obtener los mejores puestos en estas.

(35) García Solís (s. a.): 62-64. 
del auge del corporativismo de profesionales y empleados «de cuello blanco» tanto en España como en toda Europa y un factor de su extensión en los medios hacendísticos. En el primer número se incluía un artículo de Juan de Madariaga y Suárez, conde de Torre-Vélez, exdiputado y jurídico de la Armada, en el que se sostenía:

A mi entender toda la campaña de los funcionarios del Ministerio de Hacienda debía concretarse a pedir que se hiciese extensivo a todos los funcionarios que de él dependen el Reglamento orgánico del Cuerpo de Abogados del Estado, con la sola variante de no ser una escala facultativa la escala general de la administración económica del Estado. Regulándose bajo esta diferencia el examen de ingreso, todo lo demás es de aplicación, incluso, por de contado, el admirable sistema de ascensos con sus tres turnos de antigüedad, concurso y oposición, que en la práctica está ofreciendo resultados tan brillantes (36).

El objetivo de configurar un cuerpo, la oposición de ingreso diseñada y llevada a cabo por sus integrantes como condición necesaria y los modelos de referencia se reiteraban en un suelto sin firma de la propia Revista un mes más tarde, en el que se ponderaba la «satisfacción moral» y el «entusiasmo por el bien de la colectividad» de quienes habían superado una oposición (37). Por ello, seguía el texto, los «antiguos motivos ya muy suficientes para sentir el natural espíritu de clase» (se sobreentiende que de la «clase» de empleados de Hacienda) debían completarse con los de cuerpo, con el espíritu de cuerpo, del que eran portadores los cuerpos especiales de Hacienda y los nuevos entrantes en lo que se acabaría por llamar el Cuerpo de Administración General de Hacienda. El seguimiento de la Revista de Hacienda y de su competidora, Hacienda española. Revista española defensora del funcionario y de la mejora de los servicios de la Hacienda pública, cuya publicación se inició en 1924, revela que muchos de los elementos característicos de los cuerpos especiales, y sobre todo de la abogacía del Estado, configuraron el espejo en el que se miró el «proletariado de levita», lleno «de amargura de desposeídos, de preteridos, de olvidados», como definían en 1910 un artículo editorial y un jefe de administración a los funcionarios generales de Hacienda (38). Pero la relación inversa también existió, de manera que si los abogados del Estado proporcionaron el modelo del cuerpo especial de técnicos al que aspiraban a parecerse los miembros del cuerpo general, la vieja corporación de Hacienda transmitió a los abogados del Estado su visión del Ministerio como órgano vertebrador de la Administración en su conjunto y fundamento de la acción pública (39).

(36) Revista de Hacienda, 4. XII. 1905, n. ${ }^{\circ} 1$.

(37) Revista de Hacienda, 15. I. 1906, n. ${ }^{\circ} 7$.

(38) «Emilio Riu» y José León Villanueva, «Cuestiones económicas», en Revista de Hacienda, 23. II. 1910, p. 221

(39) Una y otra vez aparece en los escritos de los abogados del Estado la tesis de que la reforma administrativa clave es la de Hacienda: su organización, señala UBIERNA (1932: 74), es «un problema nacional», casi el problema administrativo por excelencia. 
No contamos con revistas de época de los abogados del Estado, cuyos «intereses» se defendían por otros medios, acordes con un cuerpo de élite dentro de la Administración. Pero otras fuentes nos permiten identificar las ideas corporativas en las que se reconocían: en concreto los discursos en actos colectivos en los que cabe suponer que los oradores jugaban precisamente con las imágenes y conceptos compartidos, es decir, con los que configuraban la base de la identidad colectiva. En 1899, poco antes de que Torre-Vélez defendiera el modelo de la abogacía del Estado para toda la Hacienda, los componentes de este cuerpo se reunieron para homenajear a los directores generales de lo Contencioso entrante y saliente (40). En las sucesivas intervenciones de ambos y de los miembros ilustres del Cuerpo se destacaron varios rasgos. Los abogados del Estado eran una «familia de sabios»: la metáfora de la familia se repitió en las intervenciones, como también la de «hermanos» bajo la paternal mirada de las autoridades corporativas. Pero la sabiduría fundada en el estudio y la disposición al trabajo no estuvieron menos presentes.

Es importante señalar que el talento y la laboriosidad sin límites de los abogados del Estado fueron subrayados para sostener su capacidad de cumplir su servicio público y completarlo con la actividad profesional privada, largamente defendida, lo que sin duda implica que estaba siendo objeto de críticas. Pero más allá de que se tratase de una defensa coyuntural, la identificación del valor corporativo con la capacidad de repartir la dedicación entre lo público y lo privado nos devuelve en parte a esa peculiaridad de los cuerpos especiales decimonónicos de compatibilizar ejercicio público y privado y regular el cuerpo y la profesión a la vez. Desde luego en el caso de los abogados del Estado no podían aspirar al control de la abogacía, como hacían los ingenieros civiles con la ingeniería, pero sí a una posición colectiva muy fuerte en la gestión de contenciosos entre los particulares y la Administración.

Esta familia de hombres de talento y elevada capacidad de trabajo no constituía empero una comunidad de iguales. La disciplina del cuerpo, sometido a sus autoridades y a sus mayores, era su tercer atributo. Disciplina que se unía a su caballerosidad: los abogados del Estado eran caballeros, por «su alto sentido de la moralidad y de la justicia» pero además porque «todos y cada uno» tendían a actuar como «guardianes y vigilantes de la honra» de los demás, es decir, que el cuerpo se imponía a las desviaciones individuales. Finalmente, el cuerpo tenía un objetivo común de servicio: ser el «más firme sostén y el organismo más fuerte de la Administración». Los abogados del Estado debían erigirse en defensores del Estado frente a «las invasiones de las banderías», es decir de los políticos, e «infiltrar en el seno de [los organismos de la Administración] el espíritu moral y jurídico de que necesitan estar animados». Una misión de tanta mayor relevancia por cuanto que «la disciplina social» andaba «relajada»y «arriba y abajo parece que predominan los intereses que encuentran mejores

(40) Recuerdo (1899). 
valedores, y se ha producido un atomismo, una anarquía, una disgregación». No muy diferentes fueron las grandes líneas de los discursos pronunciados en marzo de 1931 con motivo del cincuentenario de la abogacía del Estado. El duque de Maura, ministro de Trabajo, subrayó «la honorabilidad, probidad y espíritu de cuerpo» de los abogados del Estado, así como su «disciplina» y su «defensa del interés público», mientras que Ventosa, ministro de Hacienda, hacía del cuerpo «símbolo de la defensa del Estado» y lo ofrecía como modelo a una sociedad dominada -como se decía también en 1899- por la defensa de intereses individuales (41). En el mismo acto, Xavier Cabello Lapiedra, un abogado del Estado que hacía compatible sus tareas funcionariales con la escritura, leyó varios capítulos de un libro en preparación en que se hablaba de la gran familia de grandes juristas que se reunían en esa élite del Ministerio de Hacienda. Desafortunadamente todo parece indicar que la llegada de la II República un mes después desaconsejó la publicación de la obra.

Todos y cada uno de los elementos e imágenes en que se fundaba la identidad corporativa tenían implicaciones para la visión del Estado, aunque desde luego no quepa establecer una relación lineal entre pertenencia a un cuerpo, aceptación de su discurso colectivo y posición política. En un plano general la noción de lo público de la abogacía del Estado bebía de la teoría del Estado coetánea y en especial de la escuela francesa del servicio público, con autores de referencia como Duguit y Hariou, y de Jellinek, el gran renovador alemán de la Staatslehre. En las oposiciones de entrada al cuerpo de Abogados del Estado una parte constante y amplia del temario estaba integrada por lecciones de derecho político. En sí esto ya revelaba la pretensión universalista de un cuerpo que ni mucho menos circunscribía su ámbito de actuación a Hacienda, aunque tuviera en este ministerio su centro, lo cual, como ya hemos explicado, no resultaba irrelevante. Los restantes cuerpos hacendísticos también tenían algunos temas de esta disciplina jurídica aunque con un peso mucho más restringido, temas que resumían -en ocasiones dejaban en su mínima expresión- las concepciones presentes en las oposiciones de la abogacía del Estado (42). Es difícil calibrar la relevancia de los textos destinados a la memorización por parte de los opositores desde el punto de vista de los imaginarios de Estado. Algunos de sus autores eran abogados del Estado y otros eran profesores universitarios: no cabe encontrar grandes diferencias entre unos y otros por cuanto que ambos se fundaban en una selección de los manuales generales de cada periodo. Pero sí podemos presumir que la estructura de los temas y las definiciones, tipologías y afirmaciones que contenían ordenaban en un plano abstracto las visiones de la cosa pública entre quienes tan trabajosamente tenían que memorizarlas y recitarlas, máxime teniendo en cuenta que su éxito se juzgaba según el grado de

(41) Las referencias a las palabras de Maura en $\mathrm{La} \mathrm{Voz,} \mathrm{11.03.1931.} \mathrm{Las} \mathrm{de} \mathrm{Ventosa} \mathrm{en}$ $A B C, 11.03 .1931$.

(42) Véase por ejemplo la parte sobre el Estado en MARTínez CABAÑAS (1905). 
fidelidad de sus exposiciones y escritos a los manuales de referencia. De la selección de manuales consultados, voy a extraer algunos rasgos comunes de la caracterización del Estado (43):

1. En primer lugar todos los manuales hacían del Estado un órgano creador, realizador y protector del derecho: en los de la Restauración, subrayando la vis coactiva de la acción pública, mientras que en la segunda y en la tercera década de siglo el énfasis pasó a estar en el servicio al derecho y, a través de él a la sociedad (44).

2. En segundo lugar el Estado era una organización «necesaria»y «permanente».

3. La permanencia no impedía su evolución, descrita en términos muy diferentes en los manuales anteriores a la Gran Guerra y en los posteriores, pero movida en uno y otro caso por un «avance de la civilización».

4. La dimensión organizativa nos lleva al cuarto rasgo: el Estado quedaba encarnado en su Administración, el medio fundamental de la acción pública.

5. En quinto lugar, el Estado se describía mediante la metáfora del organismo, como ente vivo y compuesto.

Los tres primeros elementos de esta caracterización implicaban una visión ahistórica y naturalizadora, que convertía determinados rasgos del Estado liberal en rasgos del Estado e identificaba con este cualquier tipo de sistema político. Contribuían a configurar una ortodoxia frente a los ataques al Estado o al Estado burgués, por parte de anarquistas y socialistas, e incluso a la contraposición entre las instituciones sociales y el poder público por parte del catolicismo político (45). Adicionalmente resultaban compatibles con diversos proyectos de acción pública. Podían respaldar un proyecto de Estado todavía liberal como en Pérez Crespo y López Navarro, quienes haciéndose eco de Jules Simon, sostenían que «los derechos y funciones del Estado nacen de la necesidad social; esta es la medida de aquellos, de suerte que, en proporción que la necesidad disminuye por el progreso y la civilización, disminuyen los derechos y funciones del Estado» (46). Pero también modelos intervencionistas, de mayor peso, a partir de la Gran Guerra. Con todas las prevenciones que abrigaba respecto a los políticos republicanos, Calvo Sotelo estaba dispuesto a aceptar en 1931, al comentar la constitución republicana, que «la economía

(43) Los manuales son: Pérez Crespo y López Navarro (1902); Gabriel y Galán y Díez Gómez (1912); Calvo Sotelo (1927); y García Labella (1935).

(44) Se confirma en las referencias de estos manuales una evolución temporal de las visiones teóricas del Estado coherente con la defendida por VARELA (2008: 489).

(45) El proyecto de hacer del Estado una realidad que no cabe discutir se sitúa como base de la propia «doxa» del Estado según la atinada interpretación de BouRdiEU (2012: 291-292).

(46) PÉrez Crespo y LóPez NAVARro (1902): 17. 
tiene que ser dirigida por el Estado. Conforme. Es de toda evidencia. Y obsérvese un curioso fenómeno: esta tesis presidió la actuación de Primo de Rivera en el orden económico. Indudablemente, el dictador fue un estatista convencido. Y eso hay que ser para rendir pleitesía al principio de la economía dirigida» (47).

Identidades corporativas y visiones del Estado se enlazaban de una forma más directa, sin embargo, en la tesis de la identificación del Estado como poder con su Administración y en la metáfora organicista. El abogado del Estado y activo publicista Eleuterio Delgado Martín, que alcanzó brevemente la cartera de Hacienda en 1907, señalaba en 1901 que era

deber esencial de los legisladores y del Gobierno prestar la necesaria atención al organismo administrativo y tender a que, por la sabiduría de sus medidas, por la equidad de sus actos y por la justicia de sus decisiones, no aparezca como un poder tiránico y enemigo del contribuyente, sino como el verdadero representante de Estado, que se inspira en el bien público, que procura la satisfacción de las necesidades sociales y que guarda el debido respeto a todos (48).

Que la Administración fuera el «verdadero representante» del Estado suponía de entrada una clara minusvaloración de los órganos políticos: no el parlamento ni los restantes órganos constitucionales ni el Gobierno sino los funcionarios constituían desde esta perspectiva la columna de la cosa pública. Pese a la defensa de la división de poderes y a la diferenciación entre poder ejecutivo y administración, extensísimas eran las atribuciones reconocidas a la función administrativa por el abogado del Estado Ubierna en 1932: «proveer las necesidades colectivas de la sociedad» y al tiempo resolver los contenciosos a que esa provisión da lugar (49). Toda una comprensión del Estado como, sobre todo, poder administrativo que, en el caso de Hacienda, tenía una segunda componente implícita: cuando se hablaba de Administración se daba por supuesto el adjetivo central. Ayuntamientos y diputaciones eran los interlocutores territoriales de Hacienda pero no formaban parte del Estado. En 1924, al comienzo de la dictadura de Primo de Rivera, Julián Espinosa - uno de los líderes corporativos del Cuerpo General- defendía que «el Estado deb[er]ía llevar su representación económica, a ser posible, a cada pueblo de España [...] sin necesidad de confiar tan importante labor, como lo viene haciendo hasta ahora, a los alcaldes y secretarios de Ayuntamientos, representantes genuinos del caciquismo político, interesados, con fines bastardos, en las ocultaciones y en la injusta distribución de las cuotas contributivas, según su relación y compromisos con cada interesado» (50). Por lo tanto la contraposición poder/administración central y poder/administración local se doblaba en una contraposición

\footnotetext{
(47) Artículo de José Calvo Sotelo en $A B C, 17.09 .1931$.

(48) Delgado Martín (1901): 6-7.

(49) UBIERNA (1932): 21-23.

(50) Hacienda Española, 3.04.24, n. ${ }^{\circ} 3$.
} 
virtud/corrupción: una lectura que reflejaba el énfasis de la crítica regeneracionista en el caciquismo como patología política por excelencia del liberalismo español pero que enlazaba a su vez con el papel institucional de los empleados de Hacienda en el siglo XIX.

En tercer lugar, la ecuación del Estado y la Administración creaba obligaciones públicas para con los administrados, para con los contribuyentes como insistían los discursos regeneracionistas de esos años, pero también cambios en los «contribuidos» (51). «Se necesitan hombres, se dice por todas partes, para esta regeneración; se necesitan funcionarios y una Administración activa, honrada e inteligente, para construir sobre sus bases una buena Hacienda, que es el fundamento del poder y de la prosperidad del Estado» (52). Y tener esa función pública activa, honrada e inteligente pasaba por su promoción material, sostenía el jefe de la Administración de Hacienda, José León Villanueva:

Augusta es la misión de nuestro heroico Ejército, de la Magistratura y de las demás clases que integran la vida del Estado; pero no es menos augusta la de que dependemos, como encargada de allegar los recursos para subvenir a las necesidades de la Patria. Por eso, cuanto se invierta en retribuir al funcionario del orden económico administrativo, redundará en su provecho, serán gastos eminentemente reproductivos que han de traducirse en aumentos recaudatorios, cuando se la dote con lo indispensable y cuando constituya, como debe, una verdadera carrera basada en principios de estricta justicia (53).

La identidad corporativista fragmentaba la Administración Pública. Eran el «heroico Ejército», la Magistratura o el funcionario del «orden económico-administrativo» y otras «clases» las que integraban «la vida del Estado» y contribuían a su acción, cada una en su esfera. Al penetrar dentro de Hacienda se volvían a subdividir las especialidades: progresivamente lo hicieron por impuestos en el ámbito fiscal o por funciones técnicas asociadas a los impuestos (arquitectos, ingenieros de montes, ingenieros industriales) o por tareas de gestión específicas (peritos contables). Era en la especialización, aunque fuera tan universal como la de los abogados del Estado, expertos en derecho, donde se podía percibir el conocimiento y el saber-hacer que distinguía a cada cuerpo y se alcanzaba el nivel moral que garantizaban las expectativas y la autoridad de los demás «compañeros» y, llegado el caso, su actuación defensiva. Frente a las críticas a los riesgos derivados del «espíritu de cuerpo» si una tarea pública se sometía a la dirección de un miembro del cuerpo a la que se le atribuía, se

(51) Fueron múltiples los ensayos regeneracionistas pero hubo también novelas que remacharon la exigencia de esa transformación. Especialmente significativa es la dedicada a un empleado y a un ministro de Hacienda que, guiados por los «buenos consejos» de un sacerdote con fama de confesor riguroso y exigente, y de sus respectivas mujeres, acometen una reforma en profundidad de las prácticas hacendísticas: Ausín (1902).

(52) Delgado Martín (1901): 35.

(53) «Necrológica de Valentín Rubio», Revista de Hacienda, 19.01.1910, n. ${ }^{\circ} 216$. 
señalaba que el riesgo mayor era el del «desconocimiento de aquellos a los que se manda» (54).

En ese contexto, la metáfora organicista enlazaba sin solución de continuidad la defensa del grupo de pertenencia, encarnación de la competencia técnica y de la moralidad, con el servicio a la sociedad, en suma con la finalidad de armonía social y servicio público atribuida a la Administración, representante del Estado. Una explicación que estaba presente entre los abogados del Estado y los miembros de otros cuerpos especiales, así como entre el estrato superior de los empleados de Hacienda pero que era fácil de trasladar a todos los funcionarios: «los intereses del Estado nunca [son] incompatibles con las aspiraciones muy legítimas de los funcionarios pues su prosperidad depende de la mayor eficacia y mejor cometido de la función que han de desempeñar para que sea más amplia y beneficiosa la misión tutelar augusta del Estado» (55).

La cualificación y las virtudes de los funcionarios nacían de su forma de selección y de su trabajo en el servicio a los demás. Desde luego podía haber frutos podridos, frente a los que se reivindicaron (y consiguieron en 1918) los tribunales de honor de compañeros de cuerpo (56). Pero nada comparable al que se asociaba al juego político, a las «banderías». La contraposición entre funcionarios y políticos, garantes los primeros y beneficiarios los segundos de la existencia del Estado y el cumplimiento de sus funciones, alcanzó su máxima expresión en el periodo de la dictadura de Primo de Rivera. Poner al descubierto «los inmundos manejos que la política llevó a la Administración española» de Hacienda, era el objeto del libro del periodista Isidro del Campo en 1925 que reunía sus cartas al dictador (57). En la mirada del abogado del Estado y ministro dictatorial, Calvo Sotelo, «los intereses políticos y las conveniencias de partido» se contraponían a la presión tutelar del Estado «condición de posibilidad del orden social» (58). No voy a extenderme en el alcance del discurso antiparlamentario de los años de la Gran Guerra y de la década siguiente, que

(54) Dirección General de lo Contencioso (1899): 15.

(55) Hacienda Española, 25.04.1924, n. ${ }^{\circ} 6$.

(56) Los tribunales de honor los defendía explícitamente Luis Arévalo en Revista de Hacienda, 8.05.1906, $\mathrm{n}^{\circ}{ }^{\mathrm{o}} 23$, con las siguientes palabras: «Si a jefes y a compañeros hemos encomendado el aquilatar y medir el mérito de cada uno, seamos lógicos y encomendemos a los mismos el juzgar de su honor y su honradez; cuanto más estrecho es el vínculo de compañerismo, cuanto más alta idea de su misión tienen los distintos Cuerpos de un organismo colectivo, más y más interés tienen en purificar sus escalas. Ese sistema de los Tribunales implantado se halla en la mayor parte de las naciones modernas, y en todas funciones con éxito nunca desmentido, y en la nuestra practícase con excelente resultado entre los militares y entre los ingenieros civiles». Sobre los tribunales de honor: VILLACORTA (1989): 329-331.

(57) CAMPO (1925). El autor señala que las estrechas conexiones entre el mundo de la política y la prensa (en cuyos consejos de redacción según él era frecuente la presencia de los empleados de Hacienda) impedía además la denuncia pública de la corrupción hacendística derivada del caciquismo de todo tipo: Campo se muestra especialmente duro con Blasco Ibáñez y sus «manejos» en Valencia.

(58) Calvo Sotelo (1935): 99. 
tuvo apoyos importantes en voces funcionariales: solo quiero subrayar que entre estas, la contraposición se tendió a efectuar en términos de competencia técnica y conocimiento de la actividad estatal frente a politiqueo, retórica y demagogia (59). Esta defensa de la meritocracia, llevada hasta el extremo, podía conducir al rechazo explícito de la democracia como sistema político. El ya mencionado José Calvo Sotelo, desde posiciones manifiestamente autoritarias, vinculaba incompetencia técnica y democracia en un discurso enraizado en el ethos de cualquier grupo elitista, incluido desde luego el suyo:

La democracia es la improvisación y así hemos visto abogadillos de tercer orden desempeñar una después de otra casi todas las carteras ministeriales y a políticos de mesa de café queriendo pasar por estadistas, y boticarios por marinos. Y todos sirven para todo, con lo cual queda logrado que los que sirven para algo no puedan utilizarse para nada (60).

No cabe desde luego atribuir al conjunto de los cuerpos funcionariales, ni siquiera al cuerpo que constituyó su referencia en Hacienda, la abogacía del Estado, una inclinación antidemocrática, por más que la apuesta tecnocrática bordease siempre esa opción, en unos casos, y la reforzase, en otros. Las denuncias de la política y los políticos de diversa ideología actuaban en su discurso como una afirmación del saber administrativos (y económico) de cada cuerpo, más que como una propuesta compartida de sistema político. De hecho las críticas al «politiqueo» también servían para realzar la figura de los auténticos hombres de Estado, de los «estadistas». Entre ellos se hallaban los creadores de los distintos cuerpos (Camacho entre los abogados del Estado, Navarro Reverter entre los profesores mercantiles...) pero también otros benefactores que les habían prodigado sus favores desde el poder. José Calvo Sotelo, abogado del Estado, ministro de Hacienda en la dictadura y autor del Reglamento del Cuerpo de 1925, que consolidó la posición de la abogacía del Estado dentro de la Administración, cerrando su carácter de cuerpo especial, fue en 1931 objeto de una «formidable manifestación de entusiasmo espontáneo, cordial, unánime» por parte de los abogados del Estado con motivo del cincuenta aniversario del cuerpo, y ello a pesar de tratarse de unos «momentos, tristes para él, en los que la injusticia pretende herirle y la incomprensión negarle» (61). El estadista, objeto del entusiasmo colectivo, cumplía un papel importante dentro de los discursos corporativos. Estos tendían a constituir un imaginario en el que el Estado era presentado como sinónimo de una Administración jerarquizada, en

(59) Hay una buena síntesis del antiparlamentarismo en Rey Reguillo (1998).

(60) Discurso del teatro Principal de Tarrasa, 28 de abril de 1935, reproducido en CALvo SOTELO (1958): 93.

(61) La adhesión del cuerpo a Calvo Sotelo está relatada en una carta anónima a La Nación, 12.03.1931. El anonimato del autor y el texto en sí indican la dificultad política de un pronunciamiento favorable al ex-ministro que no aparece en ninguna otra de las muchas crónicas periodísticas. Quizá el autor exagere el apoyo de los abogados del Estado a su compañero, aunque lo que cuenta resulta muy verosímil. 
la que la suma de los cuerpos produciría por sí misma el mejor nivel de servicio público y sus opiniones constituirían la base de la normativa eficaz. Un imaginario en el que, en consecuencia, los «buenos» políticos tenían que limitarse a coordinar las actuaciones concretas de los cuerpos en el desempeño de sus funciones públicas: convertirse, en definitiva, en expertos en superar el haz complejo de intereses particulares y ambiciones de poder propias de los hombres políticos y en líderes y defensores de los funcionarios, constituyendo así en cierto sentido el cuerpo ideal de los estadistas.

Martínez Pérez, en la conclusión de un artículo sobre la historia de la élite de la función pública española, sostiene que esta nunca desarrolló «sentido de Estado» y que sus integrantes no «fueron sostenedores de los intereses generales», unas carencias que atribuye a la persistencia de la «vieja lógica de oficio», en cuyo eje se hallaba la concepción patrimonial de los empleos públicos (62). Explícitamente este autor sitúa en Francia unos imaginarios de Estado diferentes, que hicieron posible que las élites funcionariales rompieran con la lógica del oficio antiguorregimental y llegaran a erigirse en portadoras de intereses generales. En España esa ruptura llegó de forma incompleta y de la mano de un proceso de recomposición de las identidades profesionales que se trasladó a la Administración, haciendo del corporativismo profesional (y ya no de oficio en el sentido antiguorregimental) el eje de las reformas administrativas.

No creo por mi parte que las élites de Hacienda, ni las de Fomento ni las de otros ministerios que reconocían o se vieron forzados a reconocer en Hacienda el eje de la burocracia española, carecieran de «sentido de Estado». Mantuvieron la identificación de este con la Administración con la que los administrativistas en el siglo XIX habían construido la cultura del Estado en España (63). Pero a su vez reivindicaron que los cuerpos de especialistas, portadores de conocimiento y de moral superiores, eran los elementos natural y legítimamente constitutivos de la Administración. Dados los rasgos de esa fusión de dos tradiciones de origen y alcances distintos, resulta difícil encontrar en los portavoces de las élites funcionariales grandes declaraciones explícitas sobre las funciones específicas del Estado, sobre su modelo político concreto, sobre el alcance de la intervención estatal...: los funcionarios debían ceñir sus pronunciamientos a sus campos de actuación, demostrando no solo ser expertos sino su rechazo de quienes intervenían en los debates sin serlo. Pero en su imaginario organicista, en la tesis de que en el cumplimiento por parte de cada cuerpo de su función específica se hallaba la clave de una Administración eficaz y por ende de un Estado que lograra sus fines, residía un sentido de Estado con relevantes consecuencias para la historia de lo político en el siglo XX español.

(62) Martínez PÉRez (2009a): 479.

(63) PORTILLO (2002): 300. 


\section{CONCLUSIONES}

En la transición entre el siglo XIX y el siglo XX, se puso en marcha en la Hacienda Pública un proceso de redefinición de los medios administrativos. Pese a que los puestos burocráticos habían actuado como un botín político de gran importancia para el funcionamiento de la élite política a lo largo del reinado de Isabel II y del Sexenio, y aunque ese papel lo siguieron desempeñando en la Restauración, la experiencia democrática y los ejemplos de otros países alentaron la adopción de reformas administrativas, aparentemente menores. Entre ellas se halló la ruptura de la corporación de empleados de Hacienda mediante la aparición de un cuerpo especial, calcado sobre los existentes en otros ministerios, en especial en Fomento, y sobre determinados rasgos de los ya presentes en el ramo de Aduanas: el de abogados del Estado. Se trataba de un paso pequeño por cuanto que los herederos de los oficiales letrados del Estado establecidos en 1868 tenían una función tributaria limitada a una figura menor en términos recaudatorios, lo que pronto se conocería como impuesto de derechos reales, y tareas jurídicas vastas, aunque no centrales en el funcionamiento de la Hacienda. El afianzamiento del nuevo cuerpo, su adquisición de derechos y funciones que lo convertían en una corporación de élite y su trayectoria expansiva hacia otros ministerios favoreció la emulación de la fórmula corporativa y la construcción de nuevos cuerpos, en especial en la primera década del siglo Xx, si bien no se produjo una plena corporativización del Ministerio -y aun así con diversas ambigüedades entre las que no era la menor la importancia numérica del cuerpo generalista- hasta 1918 y el triunfo pleno de los cuerpos especiales se demoró hasta la dictadura de Primo de Rivera y sobre todo a la franquista.

La multiplicación de los cuerpos especiales y la traslación de algunos de sus rasgos a los cuerpos técnicos administrativos contribuyeron a configurar y a difundir nuevos discursos corporativistas, en cuyo eje se hallaban presentes determinados «imaginarios de Estado». No podía ser de otra manera, tratándose como se trataba de cuerpos de servidores del Estado. Al tiempo mantuvo su fuerza la tradición hacendística del siglo XIX de construcción estatal por confrontación directa con los pueblos y las provincias y de defensa de los auténticos intereses públicos frente al carácter subordinado y dependiente de los otros centros ministeriales. Hacienda retomó desde la primera década del siglo XX su liderazgo en la génesis y difusión de modelos y discursos sobre la Administración Civil.

Los discursos elaborados por los cuerpos superiores de Hacienda no fueron coherentes internamente ni tampoco fueron estáticos: muchos de sus rasgos se consolidaron durante la crisis de la Restauración, cuando se recrudecieron los conflictos funcionariales, y bajo el régimen primorriverista. No obstante cabe encontrar en ellos determinados rasgos comunes, que se inspiraron en el construido y difundido por los abogados del Estado, al fin y al cabo el ejemplo de trayectoria de éxito al tiempo que grupo reconocido como élite intelectual 
del Ministerio. La identificación del Estado con la Administración, la exclusión de las administraciones provincial y local del poder estatal (e incluso su percepción como elementos contrarios a este), la afirmación de una Administración gestionada por técnicos especializados y de moral superior -garantizada por la propia organización corporativa- y la limitación de la presencia de la política, entendida como conflicto de intereses parciales y contrapuesta en consecuencia a los intereses generales que encarnaban los funcionarios, fueron algunas de las ideas fuerza en las que convergían las visiones de los nuevos cuerpos estatales y del Estado al que servían. Las fisuras que en el Estado y la Administración podían producir los cuerpos y sus conflictos competenciales se remitían a un vago organicismo que hacía de la eficacia en cada esfera la clave de la eficacia del todo.

Este corporativismo tecnocrático no era desde luego una especificidad española. La posible especificidad fue su articulación conflictiva con los proyectos de Estado de las sucesivas clases políticas que dominaron el país entre la Restauración final y la Guerra Civil. La llamada Hacienda transicional revela que la suma de intereses-discursos de cuerpo podía resultar en reformas globales, aunque fueran desequilibradas y parciales. Otra cuestión diferente es que ese sentido de Estado, fragmentario y particularista pero guiado por una cierta lógica común, no encontrase un límite ni se viese confrontado por un discurso diferente gracias al desarrollo de una clase política de nuevo cuño, precisada de una legitimidad distinta, como sucedió en la Francia de la III República. En España la oportunidad para la aparición de ese contrapeso se perdió con la destrucción de la democracia entre 1936 y 1939. El régimen victorioso de la Guerra Civil, una vez descartada su plena fascistización, acabó transformando su cúpula administrativa, organizada de forma definitiva en cuerpos, en el sucedáneo de una clase política aniquilada o marginada tras la contienda.

\section{BIBLIOGRAFÍA}

Albuera Guirnaldos, A. (1990). El cesante: análisis de un tipo social del siglo XIX. Cuadernos de historia contemporánea, 12, 45-66.

Anaya, N. (1844). El covachuelista. En Los españoles pintados por sí mismos. Madrid: I. Boix, vol. III, 428-441.

Anuario (1860). Anuario estadístico de España correspondiente de 1859 y 1860. Madrid: Imprenta Nacional.

Ausín y Donís, T. (1902). La confesión de un ministro de Hacienda. Madrid: R. Velasco, impresor.

Bourdieu, P. (2012). Sur l'État. París: Éditions Raisons d'Agir/Éditions du Seuil.

Burdiel, I., Romeo, M. I. (1993). Los sujetos del proceso revolucionario español del siglo XIX: el papel de la prosopografía histórica. Historia contemporánea, 8, 149-156. 
Calvo Sotelo, J. (1935). El capitalismo contemporáneo y su evolución. Madrid: Academia Nacional de Jurisprudencia.

- (1958). El Estado que queremos. Madrid: Rialp.

Calvo Sotelo, L. (1927). Derecho político y administrativo. Obra ajustada al programa de 31 de julio de 1924, para los ejercicios teóricos de las oposiciones a ingreso en el cuerpo de abogados del Estado. Madrid: Editorial Reus.

Campo, I. del (1925). Lo que no ha dicho Romanones. La Hacienda española en el Antiguo Régimen. Cartas abiertas al general Primo de Rivera. Madrid: Imprenta de Juan Pueyo.

Cansino Muñoz-Repiso, J. M. (2001). Evaluar al Sector Público Español. Cádiz: Servicio de Publicaciones de la Universidad de Cádiz.

Comín, F. (1988). Hacienda y Economía en la España Contemporánea, 1800-1936, Vol. II, La Hacienda Transicional (1875-1935). Madrid: Instituto de Estudios Fiscales, Ministerio de Hacienda.

Comín, F., Martorell, M. (2006). Juan Francisco Camacho: un liberal templado. En F. Comín, P. Martín Aceña y R. Vallejo (eds.). La Hacienda por sus ministros. La etapa liberal de 1845 a 1899 (pp. 369-403). Zaragoza: PUZ.

Cuenca Toribio, J. M. y Miranda García, M. S. (1992). Sociología ministerial de la Restauración (1875-1902). Revista de estudios políticos, 78, 71-104.

Delgado Martín, E. (1901). Gobierno y administración de la Hacienda. Madrid: Tipografía de los Hijos de M. G. Hernández.

Dirección General de lo Contencioso del Estado (1899). Memoria redactada por la Dirección general de lo Contencioso del Estado en cumplimiento de lo prevenido en el art. 35 del Reglamento orgánico de 9 de agosto de 1894 comprensiva de los servicios prestados pos la misma y por el Cuerpo de Abogados del Estado en el año 1898. Madrid: R. Velasco, impresor.

Dreyfus, F. (2000). L'invention de la bureaucratie. Servir l'État en France, en Grande Bretagne et aux États-Unis (XVIIIe-XXe siècle). París : La Découverte.

E. O. H. (1872). Los funcionarios públicos. Hacienda. Colección de apuntes históricos. Madrid, Imp. de López Vizcaíno.

Escalafones (1929). Escalafones de los cuerpos generales de la Administración de la Hacienda Pública, abogados del Estado, Tribunal Supremo de la Hacienda Pública, ingenieros industriales, profesores mercantiles, auxiliares administrativos del catastro de la riqueza rústica, delineantes del catastro de la riqueza rústica y oficiales del cuerpo general de la Administración Pública según los servicios prestados a la misma correspondientes al año 1928. Madrid: Imprenta y encuadernación de Julián Espinosa.

Gabriel y Galán, B. y Díez Gómez, I. (1912). Apuntes para la contestación al programa de oposiciones á ingreso en el Cuerpo de Abogados del Estado. Tomo Segundo: Derecho político, derecho administrativo y legislación de Hacienda. Madrid: Imprenta de la Sucesora de M. Minuesa de los Ríos.

García de Enterría, E. (1985) [1972]. La Administración española. Madrid: Alianza.

García García, C. (2006). Manuel García Barzanallana: un conservador en la época del conservadurismo. En F. Comín, P. Martín Aceña y R. Vallejo (eds.). La Hacienda por sus ministros. La etapa liberal de 1845 a 1899 (pp. 263-298). Zaragoza: PUZ. 
(2007). Los primeros cuerpos inspectores, 1899-1936. En J. Pan-Montojo, (coord. ). Los Inspectores de Hacienda en España: una mirada histórica (pp. 2756). Madrid: CEF.

García Labella, J. (1935). Nociones de derecho político y legislación administrativa (obra ajustada al programa de 23 de enero de 1933 para las oposiciones a ingreso en el Cuerpo de Abogados del Estado). Madrid: Reus.

García Monerris, C. (2000). Las utopías civilizatorias del capitalismo pensado. Historia y Política, 4, 209-229.

García Solís y Cabal, P. (s. a.). Flaquezas de la Hacienda. Avant-propos en lo personal, en lo orgánico, en lo administrativo y en lo tributario. Presupuestos y economías. Siluetas ministeriales. Post-scriptum. Madrid: Establecimiento Tipográfico de Alfredo Alonso.

Garriga, C. y Lorente Sariñena, M. (2007). Cádiz, 1812. La constitución jurisdiccional. Madrid: Centro de Estudios Políticos y Constitucionales.

Gutiérrez Reñón, A. (1987). La carrera administrativa en España: evolución histórica y perspectivas. Documentación administrativa, 210-211, 29-70.

Jiménez Asensio, R. (1989). Políticas de selección en la Función Pública Española (1808-1978). Madrid: INAP.

Luis, J. P. (2002). L'utopie réactionnaire. Épuration et modernisation de l'État dans l'Espagne de la fin de l'Ancien Régime (1823-1834). Madrid: Casa de Velázquez.

Martínez Cabañas, J. (1905). Manual del opositor de Hacienda. Desenvolvimiento metódico de temas del programa de oposiciones a oficiales cuartos de Hacienda Pública. Madrid: Tipografía de J. Espinosa y A. Lamas.

Martínez Pérez, F. (2009). De la pluralidad de fueros al fuero de la Administración (1834-1845). En M. Lorente Sariñena (dir.). La jurisdicción contencioso-administrativa en España. Una historia de sus orígenes (pp. 223-266). Madrid: Consejo General del Poder Judicial.

- (2009a). Categorías y cuerpos: altos funcionarios en España (1852-1918). Anuario de Historia del Derecho Español, LXXVIII-LXXIX, 461-480.

Martykánová, D. (2007). Por los caminos de la ciencia útil: el universo ideológico de los ingenieros de caminos a través de la Revista de Obras Públicas (1853-1899). Ayer, 63, 193-219.

Mesonero Romanos, R. de (1975). Escenas matritenses. Madrid, Austral.

Moral Ruiz, J. del (2007). Las funciones del Estado y la articulación del territorio nacional. En J. Moral Ruiz, J. Pro Ruiz y F. Suárez Bilbao. Estado y territorio en España, 1820-1930 (pp. 17-358). Madrid: La Catarata.

Nieto García, A. (1967). La retribución de los funcionarios en España. Madrid: Revista de Occidente.

- (1986). Estudios históricos sobre Administración y Derecho Administrativo. Madrid: INAP.

Palacios Escario, C. (1981). La organización de las delegaciones de Hacienda durante los últimos cien años. En Las delegaciones de Hacienda: su historia (1881-1981) (pp. 1217-1270). Madrid: IEF. 
Pan-Montojo, J. (2014). Progreso material, fomento y libertad: la economía en las culturas políticas del periodo isabelino. En M. C. Romeo y M. Sierra (eds.). La España liberal, 1833-1874, volumen II de Historia de las culturas políticas en España y América Latina (pp. 51-88). Zaragoza: PUZ.

Pérez Crespo, A. y López Navarro, L. (1902). Oposiciones al Cuerpo de Abogados del Estado. Contestaciones a las preguntas de derecho político y administrativo y de legislación especial de Hacienda contenidas en el programa publicado por la «Gaceta de Madrid» con fecha 22 de enero de 1902. Madrid: Establecimiento tipográfico de Antonio Marzo.

Portillo Valdez, J. M. (2002). Estado. En J. Fernández Sebastián y J. F. Fuentes, Diccionario político y social del siglo XIX español (pp. 295-302). Madrid: Alianza.

Pro Ruiz, J. (2007). La Administración de la Hacienda en el siglo XIX y la función inspectora. En J. Pan-Montojo (coord.). Los Inspectores de Hacienda en España: una mirada histórica (pp. 1-26). Madrid: CEF.

Raphael, L. (2000). Recht und Ordnung. Herrschaft durch Verwaltung im 19. Jahrhundert. Fráncfort del Meno: Fischer.

Recuerdo (1899). Recuerdo del banquete celebrado el 7 de mayo de 1899 en obsequio á los señores D. Federico Arrazola y D. Federico de Arriaga por el Cuerpo de Abogados del Estado. Madrid: Imprenta de los hijos de M. G. Hernández.

Rey Reguillo, F. (1998). Las voces del antiparlamentarismo conservador. En M. Cabrera (dir.), Con luz y taquífrafos. El Parlamento de la Restauración (1913-1923) (pp. 273-328). Madrid: Taurus.

Rozas Barriga, J. (1981). Los delegados de Hacienda en sus relaciones con los gobernadores civiles. En Las delegaciones de Hacienda: su historia (1881-1981) (pp. 665-682). Madrid: IEF.

Rubio Bermejo, J. A. (1981). El cargo de delegado de Hacienda: condiciones y derechos. En Las delegaciones de Hacienda: su historia (1881-1981) (pp. 965-975). Madrid: IEF.

Serrano Sanz, J. M. (2006). Pedro Salaverría. Cara y cruz de la Hacienda. En F. Comín, P. Martín Aceña y R. Vallejo (eds.). La Hacienda por sus ministros. La etapa liberal de 1845 a 1899 (pp. 229-262). Zaragoza: PUZ.

Ubierna y Eusa, J. A. (1932). El funcionario público español (sus derechos y deberes). Madrid: Castro.

Vallejo Pousada, R. (2006). Ramón Santillán González: reformador de la Hacienda liberal. En F. Comín, P. Martín Aceña y R. Vallejo (eds.). La Hacienda por sus ministros. La etapa liberal de 1845 a 1899 (pp. 91-132). Zaragoza: PUZ.

Varela Suanzes, J. (2008). Estado. En J. Fernández Sebastián y J. F. Fuentes, Diccionario político y social del siglo XX español (pp. 488-504). Madrid: Alianza.

Villacorta Baños, F. (1989). Profesionales y burócratas. Estado y poder coporativo en la España del siglo XX, 1890-1923. Madrid: Siglo XXI. 
